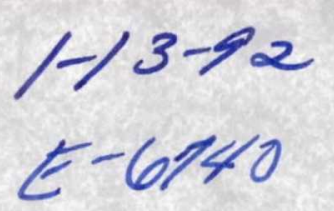

NASA Technical Memorandum 105361

AIAA-92-0240

\title{
Intensified Array Camera Imaging of Solid Surface Combustion Aboard the NASA Learjet
}

Karen J. Weiland

Lewis Research Center

Cleveland, Ohio

Prepared for the

30th Aerospace Sciences Meeting and Exhibit

sponsored by the American Institute of Aeronautics and Astronautics

Reno, Nevada, January 6-9, 1992 


\title{
INTENSIFIED ARRAY CAMERA IMAGING OF SOLID SURFACE COMBUSTION
}

\section{ABOARD THE NASA LEARJET}

\author{
Karen J. Weiland \\ NASA Lewis Research Center \\ Space Experiments Division \\ Cleveland, Ohio 44135
}

\begin{abstract}
An intensified array camera has been used to image weakly luminous flames spreading over thermally thin paper samples in a low-gravity environment aboard the NASA Lewis Research Center Learjet. The aircraft offers 10 to $20 \mathrm{sec}$ of reduced gravity during execution of a Keplerian trajectory and allows the use of instrumentation that is delicate or requires higher electrical power than is available in drop towers. The intensified array camera is a charge intensified device type that responds to light between 400 and $900 \mathrm{~nm}$ and has a minimum sensitivity of $10^{-6}$ footcandles. The paper sample, either ashless filter paper or a laboratory wiper, burns inside a sealed chamber which is filled with 21,18 , or 15 percent oxygen in nitrogen at 1 atmosphere. The camera views the edge of the paper and its output is recorded on videotape. Flame positions are measured every $0.1 \mathrm{sec}$ to calculate flame spread rates. Comparisons with drop tower data indicate that the flame shapes and spread rates are affected by the residual g-level in the aircraft.
\end{abstract}

\section{Introduction}

Flame spread over a paper surface in reduced gravity has received extensive study in drop tower facilities and has recently been observed in space experiments aboard the Shuttle. ${ }^{1-4}$ A common feature of flames produced in a reduced-gravity environment at the investigated oxygen concentrations is a low-level blue luminosity which makes it difficult to record the flame shape and position on cine film. Due to poor imaging, extinction was reported in gas jet flames when later tests, with improved photography, show a persistent flame. ${ }^{5}$ Thus, there is a need to improve the visualization system for these experimental studies.
Most reduced-gravity work on solid surface combustion has been performed at the NASA Lewis drop tower facilities, which offer 2.2 or 5 sec of microgravity, but have a high g-level impact. Shocks have been measured from 30 to $100 \mathrm{~g}$ and more. The power for all equipment is usually supplied by battery boxes onboard the experimental package. Aircraft flying Keplerian trajectories offer a longer test time, 10 to $15 \mathrm{sec}$, of reduced gravity and eliminate the shock loadings, but the g-levels are not as low as in the drop towers. Residual g-levels of \pm 0.01 to $0.02 \mathrm{~g}$ are common and effects on flame behavior due to the g-jitter also may be seen, but have not been previously quantified. Aircraft have advantages of a more hospitable environment for the use of more sensitive, delicate, and expensive instrumentation in terms of shock impact, power availability, and operator interaction that are available in the drop tower.

This paper summarizes the results of six experiments conducted aboard the NASA Lewis Learjet. These flights were undertaken primarily to demonstrate the usefulness of an intensified array camera in the detection of a flame from a solid surface combustion experiment in reduced gravity. Testing of the system in this manner is needed to verify its operation in reduced gravity, since unanticipated changes often occur to both combustion experiments and the diagnostic measurement systems when they are placed in reduced gravity. In addition, laboratory attempts to simulate the dim, low-gravity flames by reducing the pressure and increasing the oxygen mole fraction are not successful as the flames remain quite bright and sooty.

The remainder of the paper contains a description of the experimental apparatus and 
camera, a comparison between the camera and film sensitivities, the images obtained during the flights, and an analysis of the data to obtain flame spread rates for a comparison to previous drop tower measurements.

\section{Experimental Approach}

The combustion experiments were conducted aboard the NASA Lewis Learjet in a series of six flights (see Table I). The airplane is flown in a trajectory such that from 10 to $15 \mathrm{sec}$ of low gravity is attained. A three-axis accelerometer is mounted near the center of gravity of the aircraft, approximately two meters behind the combustion chamber. The $\mathrm{x}-, \mathrm{y}-$, and $\mathrm{z}$-axis outputs from the accelerometer are recorded on an oscillograph and provide an indication of the g-level present at the combustion chamber. The accelerometer does not give exact values for the experiment because it is displaced from the combustion chamber. The g-levels vary in the range of $\pm 0.02 \mathrm{~g}$, with levels during some flights being more stable.

The experimental apparatus is described in more detail elsewhere. ${ }^{4}$ The combustion chamber is an engineering model of the Solid Surface Combustion Experiment first flown aboard STS-41 in October 1990. The chamber is $512 \mathrm{~mm}$ high, and has an inner diameter of $343 \mathrm{~mm}$ and an internal volume of 39 liters. The paper samples are each $100 \mathrm{~mm} \times 30 \mathrm{~mm}$ in size. Two types of paper are used: ashless filter paper of thickness $0.19 \mathrm{~mm}$ and laboratory wipers of thickness $0.076 \mathrm{~mm}$. For each flight, one sample is loaded into a metal sample holder and placed vertically in the chamber. The vertical orientation of the paper corresponds to the $\mathrm{z}$-direction measured by the accelerometer. The chamber is evacuated overnight to dry the paper and then filled with an oxygen/nitrogen gas mixture to 1 atmosphere pressure prior to flight. A current pulse through a wire woven onto the top end of the sample ignites the paper during a low-gravity trajectory.

The intensified array camera (Xybion ISG207) is a charge injection device (CID). This camera contains an intensifier directly bonded by a tapered fiber optic to the CID imager. The intensifier consists of a photocathode, which converts the photons entering it from the lens into electrons; a microchannel plate, which multiplies the number of electrons; and a phosphor anode, which converts the electrons back into photons. The photocathode is a Generation II Red type having a spectral response range from 400 to $900 \mathrm{~nm}$. At its maximum gain of 18000 , the stated camera minimum faceplate sensitivity is $1 \times 10^{-6}$ footcandles. The amount of electron multiplication is controlled by adjusting the gain of the intensifier by setting the voltage on the microchannel plate. The intensifier can be switched electronically on and off rapidly, on the timescale of nanoseconds, and used as an optical switch, although this feature is not used for this experiment. The amplified, monochromatic image is detected by a CID array containing $242 \mathrm{~V} \times 388 \mathrm{H}$ pixels.

The camera body at $170 \times 76 \times 86 \mathrm{~mm}$ is compact and is ruggedized for durability in the presence of vibration or shock. It contains an integral high voltage power supply for the intensifier microchannel plate. Only 12 V DC at $10 \mathrm{~W}$ is required.

The intensified array camera images the edge of the paper through a window in the chamber. A $28 \mathrm{~mm}$ focal length camera lens operating at $\mathrm{F} / 2$ is used. The camera field-ofview of $105 \mathrm{~mm} \mathrm{~V} \mathrm{x} 140 \mathrm{~mm} \mathrm{H}$ provides a resolution of $0.4 \mathrm{~mm}$. For Flight 6 , an interference filter centered at $431 \mathrm{~nm}$, at the center of the $\mathrm{CH}$ radical emission in the blue, is placed before the lens. The filter bandpass is $1 \mathrm{~nm}$. The camera is operated with no gating, i.e., the exposure time is $33.3 \mathrm{~ms}$ per video frame. A light-tight shroud covers the region between the camera lens and the chamber window.

The camera video output is recorded by a portable videocassette recorder and viewed on a monitor during the experiment. The camera gain is varied manually by the experimenter by turning a potentiometer to adjust the voltage level on the microchannel plate of the camera. An on-board computer digitizes and records data on the plate voltage level. (This data for Flights 1 and 2 was not recorded, but the potentiometer positions during most of the 
experiment were noted.) Using the plate voltage, the camera gain may be determined using a prior laboratory calibration.

The videotaped flame images are digitized frame by frame using equipment at the Computer Services Division at NASA Lewis. The digitized images are electronically transferred to a workstation and analyzed using visual data analysis software. Flame positions at the leading edge on the left and right sides of the flames are measured at every $0.1 \mathrm{sec}$. Polaroid photographs of the images are taken from a monitor for display here.

\section{Camera and Film Comparison}

A comparison between film and the intensified array camera sensitivities is valuable in assisting the experimenter in choosing one camera system over another. Photometric measurements are commonly used for film and camera systems and are based on the way the human eye responds to optical radiation from 400 to $700 \mathrm{~nm}$. We compare the illuminance needed in each system to see a minimum signal. Common illuminance units are the footcandle or lux, which are a measure of the luminous flux per unit area incident on a surface. $^{6}$

We first measure in the laboratory the inherent noise of the intensified camera. A frame grabber board installed in a laboratory PC digitizes the camera video output to 8 bits ( 0 to 255 ). Image analysis software calculates the average signal level for a portion of each frame. The dark noise of the camera is measured with the microchannel plate at its highest voltage, i.e., the camera at its maximum gain, and with no light incident on the camera. The dark noise for this particular camera is relatively high, at 12 counts out of 255. We measure the maximum microchannel plate voltage to be $-920 \mathrm{~V}$. For a particular voltage setting, the camera's change in response to light level is linear over its dynamic range.

The sensitivity of the camera relative to the microchannel plate voltage is now determined. The camera without a lens is placed $30 \mathrm{~cm}$ from a white card, which is illuminated by an incan- descent light source. A UDT photometer placed next to the camera body and facing the white card measures the approximate light level reflecting off the card and impinging on the camera faceplate. The microchannel plate voltage is adjusted until a stable, digitized signal rises above the noise; this threshold signal level is selected to be 16 counts out of 255 , slightly above the dark noise measurement described above. The threshold voltage is measured for various light levels ranging from 1 to $10^{-3}$ footcandles; measurements using the photometer are not possible below this light level. A plot of this data is shown in Fig. 1. Extrapolation of the data to the maximum microchannel plate voltage shows that the camera has a sensitivity of approximately $2 \times 10^{-6}$ footcandles, near the manufacturer's stated sensitivity of $1 \times 10^{-6}$ footcandles. From this data, we set the maximum gain of the camera, 18000 , to be at the camera maximum sensitivity of $2 \times 10^{-6}$ footcandles.

The sensitivity of film is given by its photographic speed, which is defined by the American Standard Association "to be considered as inversely proportional to the minimum exposure which must be incident upon the negative material, from the scene element of minimum brightness in which detail is visible, in order that a print of excellent quality can be made from the resultant negative." 7 This definition assumes that a scene of normal brightness contrast is being photographed, contrary to the situation here. The minimum exposure is low on the optical density-log exposure curve of a photographic material. It is only slightly above the apparent exposure resulting from the fog density arising from developed, unexposed grains and the base density arising from light lost in the base material. In normal photographic work, a longer exposure than the minimum by a factor of 2.5 to 4 is recommended to allow for camera, lighting, and processing variations. To be conservative, we use the minimum exposure to make our comparison. The speed of the film is the reciprocal of the minimum exposure expressed in meter-candlesec (or lux-sec). Thus, a film with a speed of 100 has a minimum exposure of 0.01 lux-sec. 
A comparison of the sensitivities is now made between the film and the intensified array camera. The minimum faceplate sensitivity of the camera is $2 \times 10^{-6}$ footcandles. Multiplying this value by the exposure time of $33.3 \mathrm{~ms}$ per frame and converting units ( 1 lux $=0.0929 \mathrm{fc}$ ) gives a minimum exposure of $7 \times 10^{-7}$ lux-sec. This value is a factor of $\sim 10^{-4}$ times that for film with a speed of 100 . Taking the reciprocal of the camera minimum exposure gives an equivalent film speed of over 1 million. Although the camera exposure level must be above the minimum to obtain a meaningful image, the camera sensitivity is obviously much higher than film. We use the information listed above for the exposures and film speeds to establish that a camera gain setting of 1 at a gate of $33.3 \mathrm{~ms}$ is roughly equivalent to a film with a speed of 100 . Thus, for these experiments, the equivalent ASA rating is 100 times the camera gain.

The intensified array camera produces a monochromatic image of the flame due to the intensification process. In instances where color information may be desired, a filter or filter combination may be used in front of the lens. Because of the small number of pixels in the array, the spatial resolution of this particular camera is poorer than for film. Most films can resolve 50 to 100 lines per mm. ${ }^{8}$ Nonetheless, for these experiments, sufficient detail is resolved that flame shapes and spread rates are easily observed. Other cameras, such as intensified Charge Coupled Devices, are now available which have higher pixel counts and lower noise, and are more sensitive by a factor of 10 .

\section{Flame Images}

The intensified array camera observes flames for both types of paper samples burning in 21 and 18 percent oxygen without being at its highest gain. The spread rates and standoff distances for these flames could be measured and are discussed in the next section. Flame images for the remaining two test conditions are also obtained. Most of the images contain stray light reflections near the bottom of the frame, but they do not affect the image analysis or conclusions. Table 1 contains information pertinent to each of the six experi- ments. The paper type, percentage of oxygen, approximate camera gain, and average g-level in the direction parallel to the flame spread direction are given for each of the tests.

Image sequences from the ashless filter paper samples burning in 21 percent oxygen (Flight 1) and 18 percent oxygen (Flight 2) are shown in Figs. 2 and 3, respectively. The 21 percent oxygen, ashless filter paper flame burns relatively steadily for the first $10 \mathrm{sec}$, but then diminishes in intensity and almost extinguishes at $16 \mathrm{sec}$. When the aircraft begins its 2 -g pullup, the flame flares brightly. The 18 percent oxygen, ashless filter paper flame burns throughout the reduced-gravity period. It also appears to diminish in intensity near $14 \mathrm{sec}$ but recovers and continues to burn. The g-level traces for this trajectory show that the g-level varies between + and $-0.02 \mathrm{~g}$ on a timescale of seconds. During this flight, a temporary power outage aboard the aircraft near 11 sec after ignition of the paper interrupts the camera for $1.67 \mathrm{sec}$. As the videocassette recorder is battery-powered, it is unaffected and records the temporary power off and power on of the camera.

The intensified array camera gains are at 18 and 72 for most of the time during these two experiments. We estimate that film speeds of 1800 and 7200 would have been needed to see these flames. Little detail is seen in the images, partially due to the limited resolution of the detection array, but also because the images may be saturated. The problem of how to set the gain to provide the correct exposure is evident. Currently, the experimenter manually sets the gain while observing the image on the video monitor. The auto-gain feature available on this camera seeks an average video level for the entire field-of-view and tends to overexpose the flame when it is observed against a black background. During all the flights, the gain is constant to within a factor of two during most of the reduced-gravity period. Yet saturation of the flame image approximates a typical data analysis scheme in which all the pixels above a set level are set to be white and those below a set level are set to be black in order to easily 
detect the flame edge, although it precludes varying the threshold level in later data analysis.

For the remainder of the flights, laboratory wiper samples are burned. They burn more quickly than the ashless filter paper samples, as they are thinner. Two series of flame images for the laboratory wiper samples burning in 21 percent oxygen (Flight 3 ) and 18 percent oxygen (Flight 4) are shown in Figs. 4 and 5, respectively. The intensified array camera gains are 72 and 1800 , equivalent to film speeds of 7200 and 180000 .

The flame for the 21 percent oxygen, laboratory wiper burns the length of the sample in 11 sec. During the burn, some details of sooting and charring are seen. Small glowing pieces shoot out from the flame and some of the char appears to glow brightly and fold over into the flame. The width of the flame on each side of the paper changes during the burn. During this time, the lateral g-level goes from one way to the other and crosses 0 at about $6 \mathrm{sec}$; thus, the flame is wider first on one side and then the other. This is evident in Fig. 4 for the images at 4 and 7 sec.

The 18 percent oxygen, laboratory wiper flame burns brightly throughout the reducedgravity period. Near $10 \mathrm{sec}$ after ignition, the flame becomes dimmer and slows down. At this time, the $\mathrm{x}-, \mathrm{y}-$, and $\mathrm{z}$-axis accelerations are nearly 0. After a few seconds, the flame proceeds down the paper and reaches the end of the sample at $20 \mathrm{sec}$ after ignition, where it continues to burn during the aircraft pull-up. Some sooting and burning of the paper near the middle of the sample are seen during the aircraft pull-up.

The laboratory wiper sample in 15 percent oxygen (Flight 5) appears to ignite and burn for approximately 5 sec before extinguishing, as shown in Fig. 6. The camera is at its highest gain, but no flame is detected after 5 sec even during the 2-g pullup.

For Flight 6, the narrow-bandpass interference filter is placed in front of the camera lens. The test conditions of Flight 4, a laboratory wiper in 18 percent oxygen, are repeated. The camera gain is at its maximum of 18000 , but because the bandwidth of the filter is so narrow at $1 \mathrm{~nm}$, the flame can be seen only dimly, as shown in Fig. 7. The flame images appear to be snowy because of the noise of the camera when it is at its highest gain. The flame images in Flight 6, using the interference filter, are not useable for accurate flame spread measurements. We interpret this result to indicate that the filters for reduced-gravity experiments must be tested individually. For example, in this experiment, a better choice would have been a filter with a wider bandpass of $10 \mathrm{~nm}$.

\section{Flame Spread Rates}

Measurements of the flame spread rates are useful for an order-of-magnitude comparison to other reduced-gravity measurements, although they are not obtained under truly quiescent conditions and the induced velocities due to buoyancy are not known. The flame images are analyzed using a commercial visual data analysis software package. For each flame, the edge of the flame is specified to occur at a certain gray level, e.g., 60 out of 255 . The gray level chosen is that which appears to the eye to be the edge. The gray level can be varied somewhat (10 percent), and similar results for the relative positions are obtained. This level is fixed for each flame, so that it is the same from frame to frame. The software package allows the user to measure the pixel position of the specified gray level in the frame. The pixel positions are converted to distances by measuring the number of pixels between the sample holder bolts which are $25.4 \mathrm{~mm}$ apart. The origin refers to the top of the frame, approximately near the top edge of the paper.

The flame spread rates are obtained from the position of the leading edge of the flame as a function of time. The time of ignition is seen on the videotape and is marked on the oscillograph traces of the g-levels. A plot of the relative flame positions versus time from ignition for four of the tests (Flight 1-4) is shown in Fig. 8. After the first few seconds, during which ignition and stabilization occur, the flames spread steadily over the paper samples. The 
flame spread rates and flame standoffs are listed in Table 1.

The average flame spread rate for the ashless filter paper burning in 21 percent oxygen is taken from the data between 3 and $13 \mathrm{sec}$ and is $0.16 \mathrm{~cm} / \mathrm{sec}$. The flame position after $14 \mathrm{sec}$ is difficult to determine and is not measured. The average g-level for Flight 1 is one of the smoothest of the six.

Data for ashless filter paper burning in 18 percent oxygen is also shown in Fig. 8. The average flame spread rate for the ashless filter paper burning in 18 percent oxygen taken from data between 3 and $18 \mathrm{sec}$ is $0.09 \mathrm{~cm} / \mathrm{sec}$, slower than the ashless filter paper burning in 21 percent oxygen. The approximate g-level for Flight 2 oscillates between + and $-0.02 \mathrm{~g}$. The flame position advances and retreats on a timescale of seconds and appears to correlate, with some delay, with the g-level changing between positive and negative. The flame standoff changes with the g-level, as well. When the flame advances, the leading edge approaches the paper and becomes narrower; when the flame retreats, the leading edge becomes wider. The flame response to the changing g-level appears to lag by about $1 \mathrm{sec}$ early in the burn, but appears to respond quickly near the end of the burn. Both ashless filter paper flames do not move far during the reducedgravity period and so may be influenced by the presence of the ignitor.

There is little data obtained in reduced gravity for this fuel with which to make a comparison. Some unpublished data, obtained in the NASA Lewis Zero Gravity facility (Sandra Olson, private communication), show that ashless filter paper samples burning in 30 percent oxygen at 1 atmosphere have a spread rate of approximately $0.12 \mathrm{~cm} / \mathrm{sec}$. The flame images are very dim blue and difficult to analyze. The flame spread rate observed here for ashless filter paper in 21 percent oxygen is higher than that measured in the quiescent, 30 percent oxygen environment in the drop tower, probably due to the induced buoyant velocity from the residual g-level.
The laboratory wiper samples burn faster than the ashless filter paper samples, as is evident by the plot of flame position versus time for the 21 and 18 percent oxygen tests in Fig. 8, as taken from the flame images of Flights 3 and 4 . The flame for the laboratory wiper in 21 percent oxygen spreads smoothly to the end of the paper during the reduced-gravity period and the average flame spread rate is $0.8 \mathrm{~cm} / \mathrm{sec}$. The flame of the laboratory wiper in 18 percent oxygen spreads smoothly for the first $9 \mathrm{sec}$, appears to retreat momentarily, and then proceeds. The paper sample burns to the end during the $20 \mathrm{sec}$ of reduced gravity. The average flame spread rate for the laboratory wiper in 18 percent oxygen, as measured from the data between 10 and $20 \mathrm{sec}$, is $0.5 \mathrm{~cm} / \mathrm{sec}$.

Previous drop tower experiments using the laboratory wipers as the fuel show that for quiescent flame spread the molar oxygen extinction limit is 21 percent. $^{2}$ Under these conditions, the flame spread rate is measured to be $0.54 \mathrm{~cm} / \mathrm{sec}$. It is also reported that for a forced, opposed-flow velocity of $7 \mathrm{~cm} / \mathrm{sec}$, the flame spread rate is $0.87 \mathrm{~cm} / \mathrm{sec}$. In other drop tower work that involves the study of lowspeed, concurrent-flow flame spread, forced flow rates of $2.5 \mathrm{~cm} / \mathrm{sec}$ and $5 \mathrm{~cm} / \mathrm{sec}$ produce flame base spread rates of $0.5 \mathrm{~cm} / \mathrm{sec}$ and $0.7 \mathrm{~cm} / \mathrm{sec}$, respectively. ${ }^{3}$ The flame spread rate for the laboratory wiper at 21 percent oxygen in this Learjet test, $0.8 \mathrm{~cm} / \mathrm{sec}$, is higher than the quiescent drop tower measurement, but is consistent with the presence of induced velocities, both opposed and concurrent, on the order of the forced flow experiments in the drop tower.

The laboratory wiper will burn in 18 percent oxygen only if there is a flow velocity over the surface of the paper. In drop tower measurements using low opposed-flow velocities of 5 to $8 \mathrm{~cm} / \mathrm{sec}$, the flame spread rate is 0.40 to $0.64 \mathrm{~cm} / \mathrm{sec}^{2}$ In the other drop tower measurements using low-speed, concurrent-flow velocities of 2.5 and $5 \mathrm{~cm} / \mathrm{sec}$, flame spread rates of 
0.4 and $0.6 \mathrm{~cm} / \mathrm{sec}$ are observed. ${ }^{3}$ The flame spread rate of $0.5 \mathrm{~cm} / \mathrm{sec}$ measured here aboard the Learjet for a laboratory wiper burning in 18 percent oxygen is again consistent with the presence of induced velocities due to the residual g-level of the aircraft.

No data on spread rate or standoff is reported here for the laboratory wiper burning in 15 percent oxygen, as the flame extinguishes after approximately $5 \mathrm{sec}$. In the opposed-flow drop tower work discussed above, it is reported that for a low opposed-flow velocity of 4 to $6 \mathrm{~cm} / \mathrm{sec}$, the extinction limit is $\mathbf{1 5}$ percent oxygen. At this oxygen mole fraction, the flame spread rate is too slow to be measured in the short experimental time available in the drop tower and the flame is either propagating at some very small spread rate or transitioning to extinction. Similarly, for a low concurrent-flow, the extinction limit is reported to be somewhere near or above 12 percent oxygen. Those tests show that for oxygen mole fractions slightly above 12 percent, the testing times are too short to determine the ultimate fate of the flame. The average g-level of the aircraft for the first few seconds of the experiment of Flight 5 is $-0.01 \mathrm{~g}$, with a few seconds nearly $0 \mathrm{~g}$. Some concurrent velocity of the gas mixture would have been induced, but evidently it is too low to maintain the combustion of the paper.

\section{Conclusions}

An intensified array camera has successfully imaged weakly luminous flames spreading over thermally thin paper samples in a reduced-gravity environment. A comparison of film speed and camera exposure shows that the camera sensitivity is much higher than film. Images obtained using bandpass interference filters indicate that such filters for reduced-gravity experiments must be carefully selected. The residual g-level of the aircraft affects the flammability, flame shapes, and spread rates. The flammability and measured flame spread rates for the laboratory wipers in 21 and 18 percent oxygen for these "quiescent," aircraft experiments are similar to those obtained in forced-flow drop tower experiments, suggesting substantial induced velocities due to the residual g-levels are present.

\section{References}

1. Bhattacharjee, S., Altenkirch, R.A., and Sacksteder, K., "Implications of Spread Rate and Temperature Measurements in Flame Spread over a Thin Fuel in a Quiescent, Microgravity, Space-Based Environment," submitted to Combustion Science and Technology, 1991.

2. Olson, S.L., Ferkul, P.V., and T'ien, J.S., "Near-Limit Flame Spread over a Thin Solid Fuel in Microgravity," TwentySecond Symposium (International) on Combustion, The Combustion Institute, Pittsburgh, PA, 1988, pp. 1213-1222.

3. Grayson, G., Sacksteder, K.R., and T'ien, J.S., "An Experimental Study of LowSpeed, Concurrent-Flow Flame Spread over a Thin Fuel," presented at the Central States Meeting of the Combustion Institute, Nashville, TN, 1991.

4. Vento, D.M., Zavesky, R.J., Sacksteder, K.R., and Altenkirch, R.A., "The Solid Surface Combustion Space Shuttle Experiment Hardware Description and Ground-Based Test Results," AIAA Paper 89-0503, Jan. 1989 (Also, NASA TM-101963).

5. Bahadori, M.Y., Edelman, R.B., Stocker, D.P., and Olson, S.L., "Ignition and Behavior of Laminar Gas-Jet Diffusion Flames in Microgravity," AIAA Journal, Vol. 28, No. 2, Feb. 1990, pp. 236-244.

6. Smith, W.J., Modern Optical Engineering: The Design of Optical Systems, 2nd ed., McGraw-Hill, New York, 1990, p. 223.

7. Russell, M.E., chairman, "American Standard Method for Determining Photographic Speed and Speed Number," Journal of the Optical Society of America, Vol. 33, No. 8, Aug. 1943, pp. 479-486.

8. Young, M., Optics and Lasers, 2nd ed., Spring-Verlag, New York, 1984, p. 27. 
Table 1. - Summary of test conditions and results

\begin{tabular}{|c|c|c|c|c|c|c|}
\hline $\begin{array}{l}\text { Flight } \\
\text { number }\end{array}$ & $\begin{array}{l}\text { Paper } \\
\text { type }\end{array}$ & $\begin{array}{l}\text { Percent } \\
\text { oxygen }\end{array}$ & $\begin{array}{c}\text { Camera } \\
\text { gain }\end{array}$ & $\begin{array}{c}\text { Average } \\
\text { g-level, } \\
\text { g }\end{array}$ & $\begin{array}{c}\text { Spread } \\
\text { rate, } \\
\mathrm{cm} / \mathrm{sec}\end{array}$ & $\begin{array}{c}\text { Standoff, } \\
\mathrm{cm}\end{array}$ \\
\hline 1 & $\begin{array}{l}\text { Ashless } \\
\text { filter paper }\end{array}$ & 21 & 18 & 0.000 & 0.16 & 0.7 \\
\hline 2 & $\begin{array}{l}\text { Ashless } \\
\text { filter paper }\end{array}$ & 18 & 72 & .004 & .09 & .8 \\
\hline 3 & $\begin{array}{l}\text { Laboratory } \\
\text { wiper }\end{array}$ & 21 & 72 & -.003 & .8 & .9 \\
\hline 4 & $\begin{array}{l}\text { Laboratory } \\
\text { wiper }\end{array}$ & 18 & 1800 & -.001 & .5 & .8 \\
\hline 5 & $\begin{array}{l}\text { Laboratory } \\
\text { wiper }\end{array}$ & 15 & 18000 & ----- & ---- & --- \\
\hline 6 & $\begin{array}{l}\text { Laboratory } \\
\text { wiper }\end{array}$ & 18 & 18000 & ------ & --- & --- \\
\hline
\end{tabular}

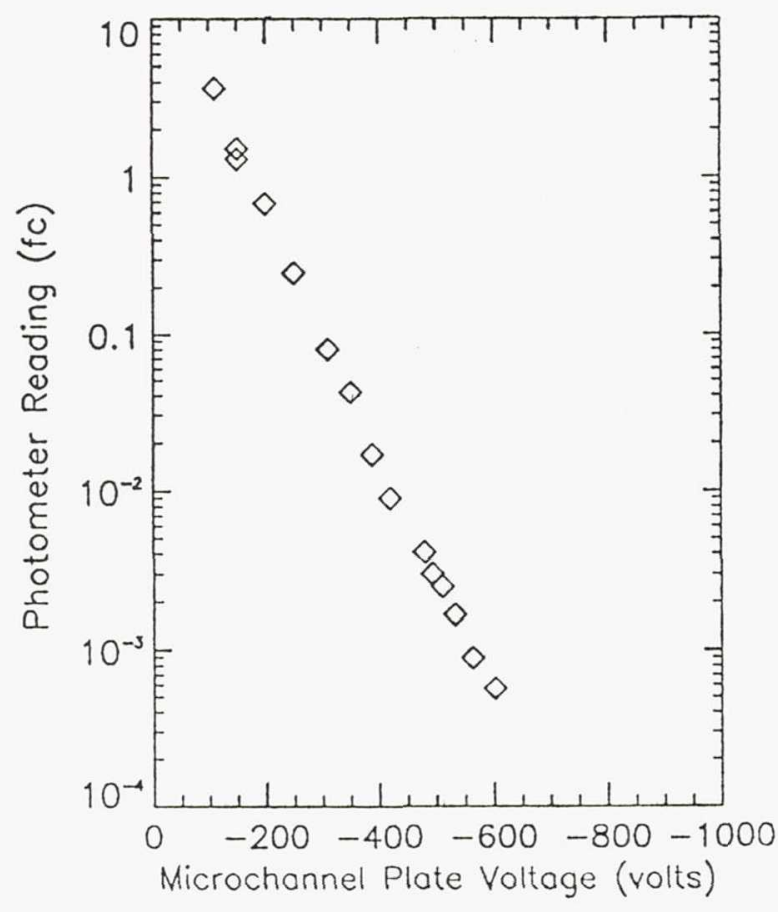

Figure 1.-Calibration of Xybion CID camera sensitivity. The microchannel plate voltage necessary to see a specifled signal level is plotted for various light levels.

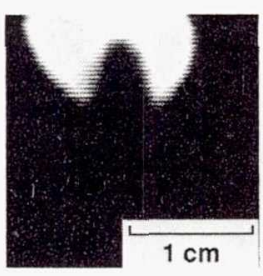

$5 s$

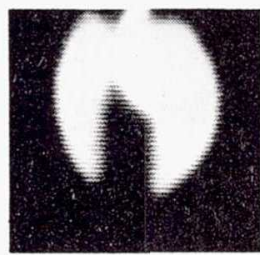

$11 \mathrm{~s}$

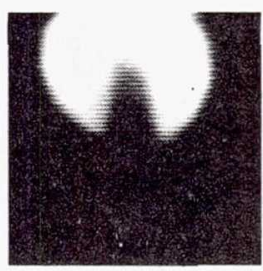

$7 s$

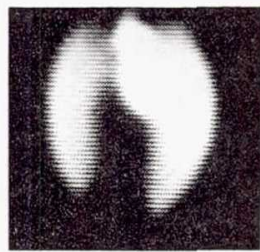

$12 s$

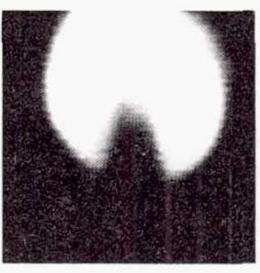

$9 \mathrm{~s}$

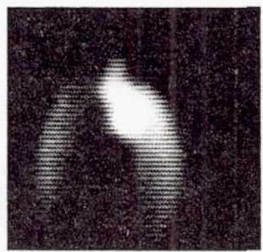

$14 \mathrm{~s}$

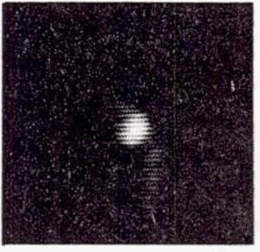

$15.5 \mathrm{~s}$

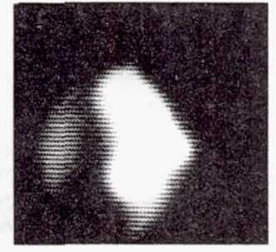

$17 \mathrm{~s}$
Figure 2.- Series of flame images for ashless filter paper burning in $21 \%$ oxygen. 

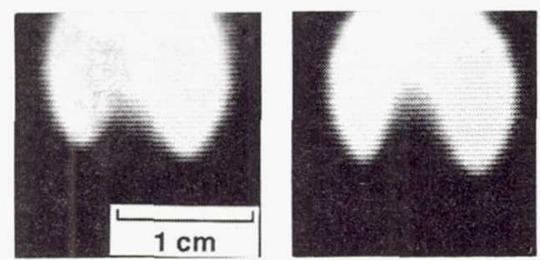

$8 s$

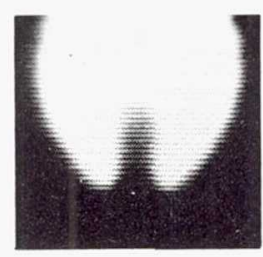

$10.9 \mathrm{~s}$

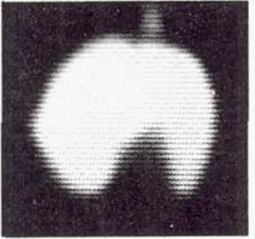

$15 s$

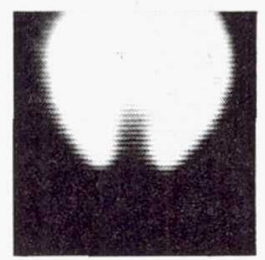

$10 \mathrm{~s}$

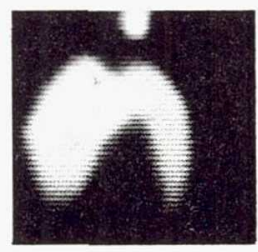

$14.5 \mathrm{~s}$
$13.4 \mathrm{~s}$

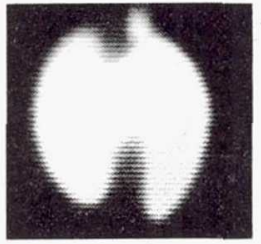

$16 s$

Figure 3.-Series of flame images for ashless filter paper burning in $18 \%$ oxygen.

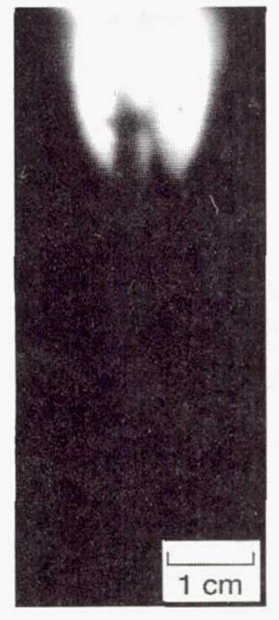

$2 s$

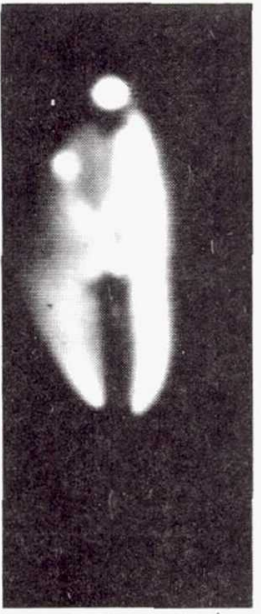

$7 \mathrm{~s}$

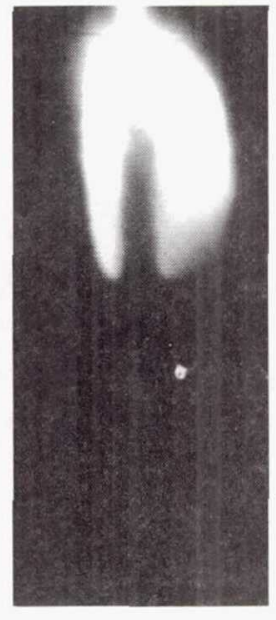

$4 s$

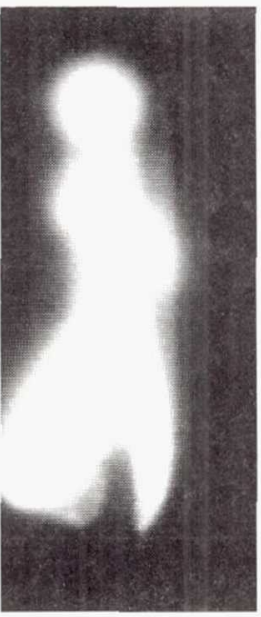

$9 \mathrm{~s}$

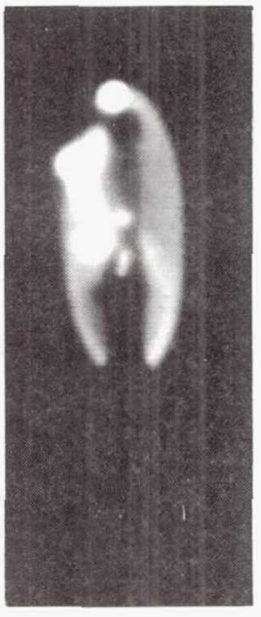

$6 s$

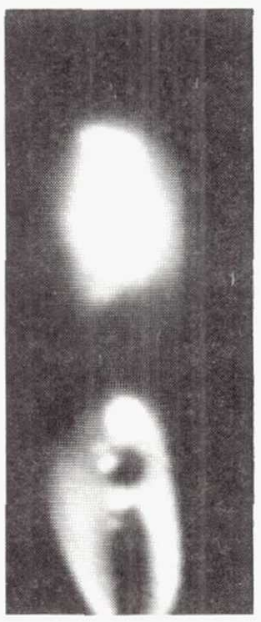

$11 \mathrm{~s}$
Figure 4.- Series of flame images for a laboratory wiper burning in $21 \%$ oxygen. 


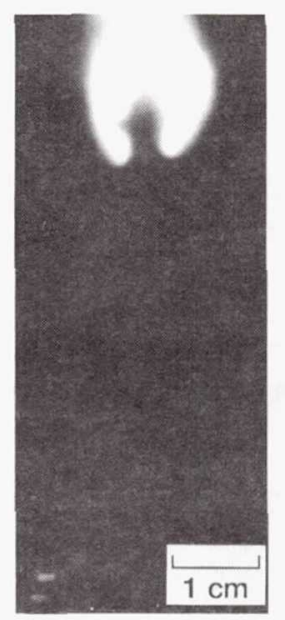

$3 s$

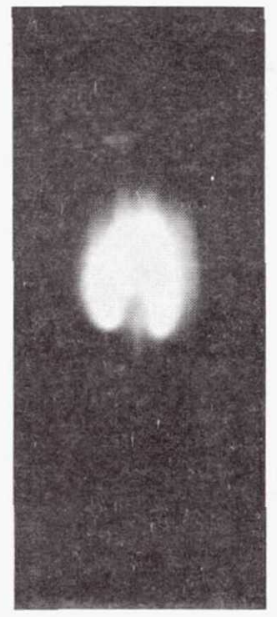

$11 \mathrm{~s}$

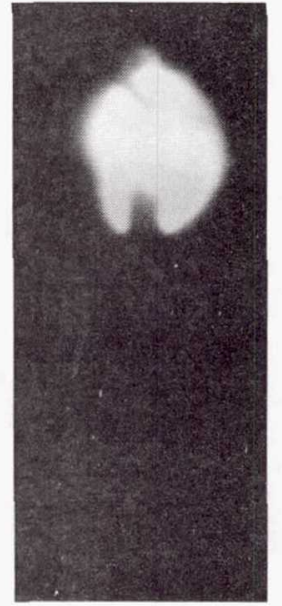

$6 s$

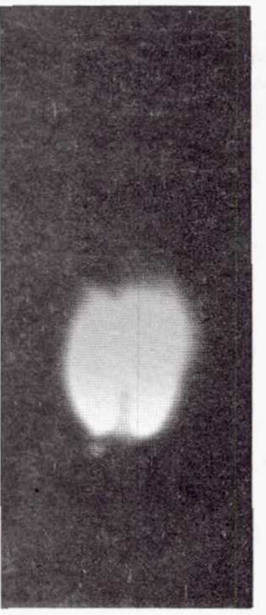

$15 s$

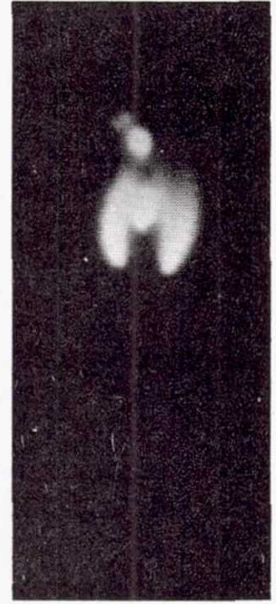

$9 \mathrm{~s}$

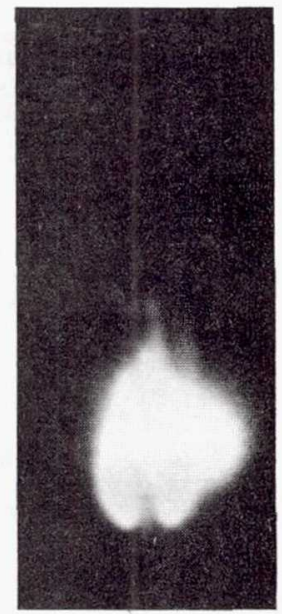

$18 s$

Figure 5.-Series of flame images for a laboratory wiper burning in $18 \%$ oxygen.

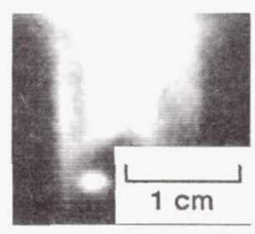

$3 \mathrm{~s}$

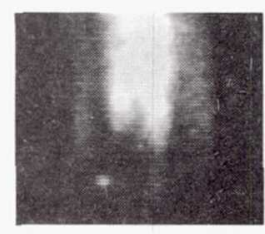

$4 \mathrm{~s}$

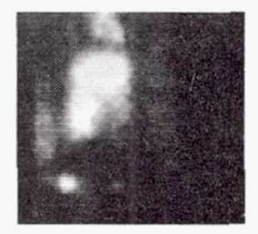

$5 s$

Figure 6.-Series of flame images for a laboratory wiper burning in $15 \%$ oxygen.

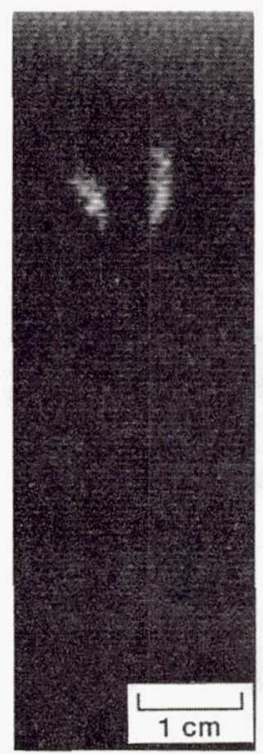

$6 s$

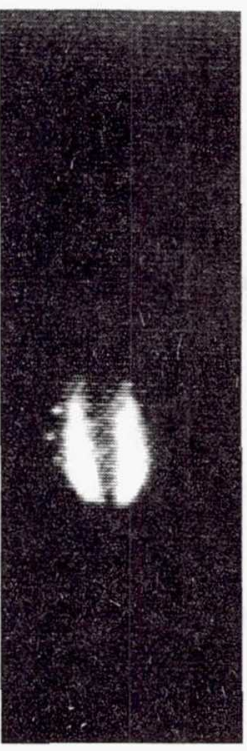

$12 \mathrm{~s}$

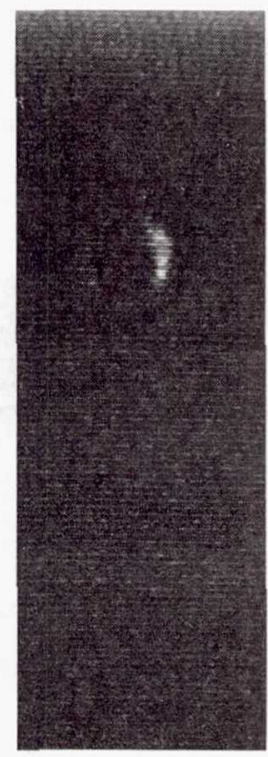

$7 \mathrm{~s}$

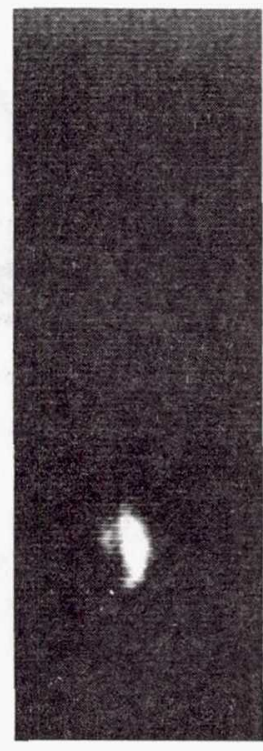

$14 s$

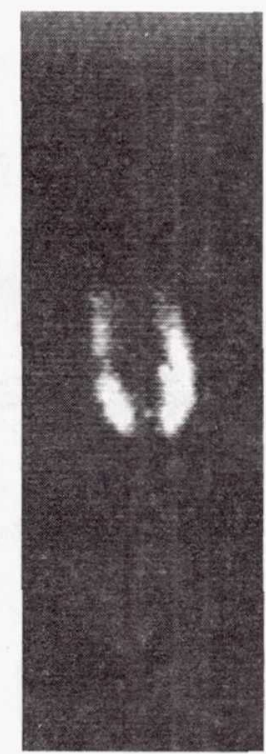

$10 \mathrm{~s}$

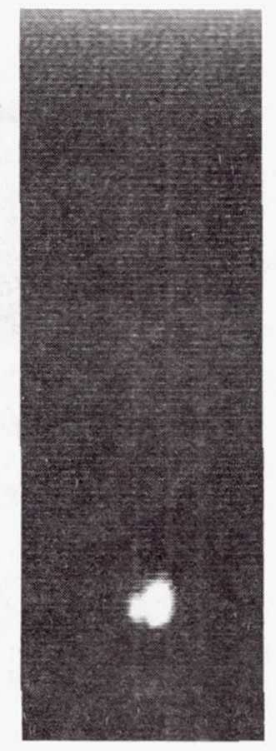

$15 \mathrm{~s}$
Figure 7.- Series of flame images for a laboratory wiper burning in $18 \%$ oxygen. A blue interference filter is used before the camera lens. 


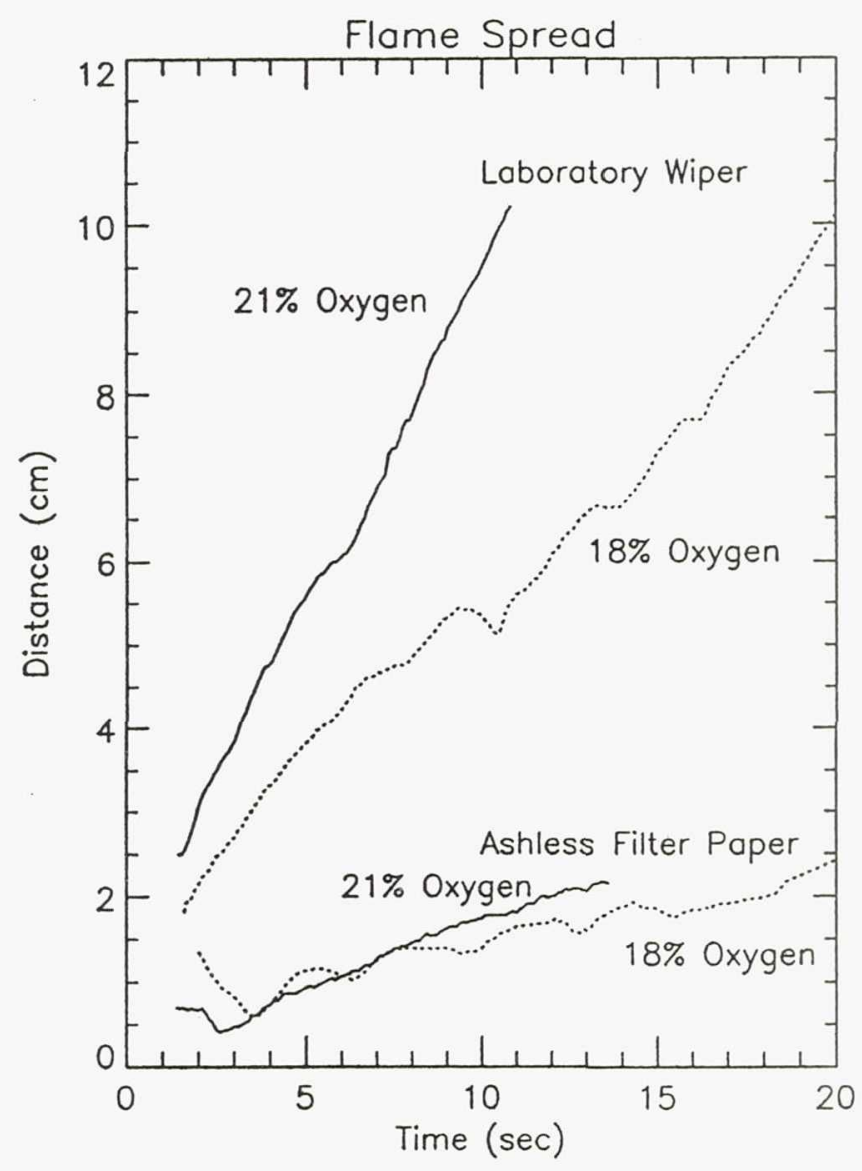

Figure 8.-Flame position versus time from ignition for ashless filter paper and laboratory wiper samples. The distance is a relative measurement. 
Public reporting burden for this collection of information is estimated to average 1 hour per response, including the time for reviewing instructions, searching existing data sources, gathering and maintaining the data needed, and completing and reviewing the collection of information. Send comments regarding this burden estimate or any other aspect of this collection of information, including suggestions for reducing this burden, to Washington Headquarters Services, Directorate for information Operations and Reports, 1215 Jefferson Davis Highway, Suite 1204, Arlington, VA 22202-4302, and to the Office of Management and Budget, Paperwork Reduction Project (0704-0188), Washington, DC 20503.

\begin{tabular}{l|l|l}
\hline 1. AGENCY USE ONLY (Leave blank) & 2. REPORT DATE & 3. REPORT TYPE AND DATES COVERED
\end{tabular}

1992

Technical Memorandum

\section{TITLE AND SUBTITLE}

Intensified Array Camera Imaging of Solid Surface Combustion Aboard the NASA Learjet

\section{AUTHOR(S)}

Karen J. Weiland

\section{FUNDING NUMBERS}

WU-694-03-0C

7. PERFORMING ORGANIZATION NAME(S) AND ADDRESS(ES)

8. PERFORMING ORGANIZATION REPORT NUMBER

National Aeronautics and Space Administration

Lewis Research Center

Cleveland, Ohio 44135-3191

E- 6740

9. SPONSORING/MONITORING AGENCY NAMES(S) AND ADDRESS(ES)

10. SPONSORING/MONITORING AGENCY REPORT NUMBER

National Aeronautics and Space Administration

Washington, D.C. 20546-0001

NASA TM - 105361

AIAA-92-0240

\section{SUPPLEMENTARY NOTES}

Prepared for the 30th Aerospace Sciences Meeting and Exhibit sponsored by the American Institute of Aeronautics and Astonautics, Reno, Nevada, January 6-9, 1992. Responsible person, Karen J. Weiland, (216) 433-3623.

12a. DISTRIBUTION/AVAILABILITY STATEMENT

12b. DISTRIBUTION CODE

Unclassified - Unlimited

Subject Category 29

13. ABSTRACT (Maximum 200 words)

An intensified array camera has been used to image weakly luminous flames spreading over thermally thin paper samples in a low-gravity environment aboard the NASA Lewis Learjet. The aircraft offers 10 to 20 sec of reduced gravity during execution of a Keplerian trajectory and allows the use of instrumentation that is delicate or requires higher electrical power than is available in drop towers. The intensified array camera is a charge intensified device type that responds to light between 400 and $900 \mathrm{~nm}$ and has a minimum sensitivity of $10^{-6}$ footcandles. The paper sample, either ashless filter paper or a laboratory wiper, burns inside a sealed chamber which is filled with $21 \%, 18 \%$, or $15 \%$ oxygen in nitrogen at one atmosphere. The camera views the edge of the paper and its output is recorded on videotape. Flame positions are measured every $0.1 \mathrm{sec}$ to calculate flame spread rates. Comparisons with drop tower data indicate that the flame shapes and spread rates are affected by the residual g-level in the aircraft.

14. SUBJECT TERMS

Microgravity; Flame spread; Combustion diagnostics

17. SECURITY CLASSIFICATION OF REPORT Unclassified
18. SECURITY CLASSIFICATION OF THIS PAGE Unclassified
19. SECURITY CLASSIFICATION OF ABSTRACT Unclassified 